\title{
Development and Applications of Microfluidic Devices for Cell Culture in Cell Biology
}

\section{Linglu Yi'1,2 and Jin-Ming Lin ${ }^{2 *}$}

${ }^{1}$ School of Science, Beijing University of Chemical Technology, Beijing 100029, PR China

${ }^{2}$ Department of Chemistry, Beijing Key Laboratory of Micronalytical Methods and Instrumentation, Tsinghua University, Beijing 100084, PR China

\begin{abstract}
Development of microfluidic culture technology combined with tissue engineering catalyzes the progress in study of cell biology. These tools will promote the understanding of physiological and pathological changes. Cancer cells and stem cells are sensitive to their surroundings, thus could be better explored by controllable microfluidic devices. In this review, we describe the ways to control cell microenvironment and explain how the influencing factors influence cellular behaviors, then present microfluidic-chip-based exemplary applications for cancer models and stem cell differentiation.
\end{abstract}

Keywords: 3D cancer model; Cell patterning; Microfluidic culture; Cell biology; Stem cell differentiation

\section{Introduction}

There is a clear need to study normal and pathological cell function under native in vivo milieu. As many of problems of interest in cell biology lie on micro scale, there is an urgent need to process studies at micro level. The miniaturization of culture system fulfills this requirement due to its features like automatic operation, highthroughput analysis highly integration of function modules and precisely control of different parameters. Among these microfluidic culture systems, 3D microfluidic culture models are powerful to improve the physiological relevance of in vitro models in study of cancer $[1,2]$. In addition, the development of in vitro models at tissue and organ level is one of the most promising microscale applications in high-throughput screening of drug toxicity. The integration of tissueengineering strategies and microfluidic technologies has recently sparked a breakthrough in adapting to morphological changes in tissue structure and function over time, providing a level of precision control that could not be achieved previously [3]. Tissues-on-a-chip and organs-on-a-chip show a more humanized character, would greatly improve the efficacy of drug toxicity screening [4,5]. Vascular structures have been constructed to explore inflammatory signals and further to connect individual organs to form a microvascular 3D networks [6]. There are a number of journal papers that are published in microfluidic culture applications in life science and some microscale $3 \mathrm{D}$ in vitro systems are commercially available for applications of anticancer drug testing [7], reflecting the growing importance of this field.

Based on our previous work, we review the development of microfluidic applications in cell biology in three sections. In the first section, how the cells and microenvironment factors are patterned and controlled to replicate vivo-like models in microfluidic devices are described and how the factors influence cell fate are discussed in terms of physical cues, cell-cell and cell-ECM interactions. The second section introduces the cell-assays based on the development of 3D microfluidic culture in the field of cancer research and stem cell differentiation. Finally, we describe potential future of microfluidic culture in cell-biology study.

\section{Cell and environment control}

Cell fate in vivo is largely affected by external factors like physical or chemical interface and interaction with other cells or matrix; therefore, it is important to precisely control these factors in in-vitro studies. Microfluidic cell cultures wins over conventional culture methods in controlling these factors both spatially and temporally, and then shedding light on mechanisms of cellular processes in vitro.
Cell patterning: Adhesion is a fundamental behavior that determines cellular behaviors like polarity, migration and apoptosis [11]. In others words, the impact of geometry by a cell and a group of cells could be studied by controlling the adhesion behavior. The adherent state of cells on surface can be governed by chemical and mechanical methods in microfluidic devices (Figure 1a). For example, Dertinger's group processed neural network construction by using surface gradients of laminin, an ECM protein important for neuronal guidance [12]. They found anon orientation toward the increasing surface density of laminin. Using a piece of hydrophobic polythyleneterephthalate (PET) film, we separated two kinds of cells on the same coverslip before the following on-line analysis of metabolism [13].

On the contrary, topographical factor shows no significant impact on cell patterning. By creating continuous sinusoidal features in PDMS, cells grown on this surface were proven to show similar alignment on completely smooth wavy and sharp corners [14].

Micro compartmentalization has enabled patterning cells in vivolike cellular arrangements by channel geometry and the physical attributes of microsystems. For example, our group investigated the quantum dot (QD) cytotoxicity on HepG2 cells cultured in agarose matrix. The 3D culture chambers were divided into close and far chambers for their different distances from the main channel [15].

Zervantonakis's group regenerated endothelial barrier in 3D microfluidic model [16]. The 3D compartmentalization enables precise investigation of distance between tumor and stromal cells, and the incorporation of macrophages (the cells that direct tumor intravasation). The distance dependence has also been studied in terms of breast cancer progression [17]. Cancer cells that in closer proximity to fibroblasts were proven to be more invasive. Therefore, in the process of cancer progression, the physical contact with fibroblasts might be the basis before the driving by soluble factors.

Fabricating microwell array on microfluidic platform is a typical

${ }^{*}$ Corresponding author: Dr. Jin-Ming Lin, Department of Chemistry, Beijing Key Laboratory of Micronalytical Methods and Instrumentation, Tsinghua University, Beijing 100084, Tel: 0086-10-62792343, E-mail: jmlin@mail.tsinghua.edu.cn

Received November 15, 2016; Accepted December 22, 2016; Published December 30, 2016

Citation: Yi L, Lin JM (2017) Development and Applications of Microfluidic Devices for Cell Culture in Cell Biology. Mol Biol 6: 182. doi: 10.4172/2168-9547.1000182

Copyright: (c) 2017 Yi L, et al. This is an open-access article distributed under the terms of the Creative Commons Attribution License, which permits unrestricted use, distribution, and reproduction in any medium, provided the original author and source are credited. 
method for cell patterning. We have made several researches by this method to control cell density gradient and for single-cell analysis [1820].

To confine groups of cells into designed geometric shape, another way that has risen up in the recent years printing by inkjet, especially for 3D model construction.Taking advantages of automatic, highthroughput and high-efficient operating of solution at micro/nano level by this method, our group have made successful progress in single cell analysis and cell patterning [21,22]. This approach allows the assembly of heterogeneous tissue structure to mimic in vivo physiological tumor model, as well as the possibility of fabricating $3 \mathrm{D}$ in vitro tumor models with large-scale, high throughput and high cell density. It is promising to produce reliable in vitro models from $2 \mathrm{D}$ to $3 \mathrm{D}$. Based on the rapid and automatic inkjet technology, different cells could be deposit in predefined patterns $[9,23]$ (Figure 1b). To construct 3D co-culture, cells can be mixed with collagen by a dual ejection [24]. Successful applications of this method were seen in exploration of breast cancer initiation and progression [25]. The 3D tumor assembly can be controlled by precisely mixing of cells and matrix substrate like gelatin and alginate, thus shows advantages in mimicking vivo-like micro environmental characteristics. Similar examples of application of cell printing had been reported in controlling the stem cells. DolatshahiPirouz [26] reported high-throughput generation of miniaturized and combinatorial cell-laden micro gel arrays for screen of various biomaterials in combination with selected soluble factors for MSC osteogenic inductive.
As previously mentioned [27], scaffold-based culture model is advantageous for simulating the in-vivo microenvironment and provide better mass transport efficiency than natural-derived materials. This structure benefits from biomaterials that support well-control of cell patterning. With the aid of computer, 3D porous bioactive scaffolds with complex architectural structures and well-defined material properties could be rapidly fabricated $[28,29]$. The second way to fabricate 3D scaffolds is electrospinning, which creates non-woven mats volume as ECM analogue scaffolds. There are two major advantages of this method: one is the cost efficiency of using very small quantities of polymers, and the other is that additional components such as copolymers and growth factors can be added to the polymer solution in the preparation process and then be incorporated into the electrospun fibers. The scaffold based models are suitable for investigation of anticancer drug mechanisms. In a recent work, a core-shell scaffold had been used to spatially assemble hepatocytes in the core and fibroblasts in the shell, which realized cell-cell interaction in a drop (Figure 1c).

Control of physical factors: Microfluidic systems can help elucidate the physical factors (such as oxygen, shear stress, geometry and temperature) that affect the behavior of cells. We had investigated the impact of oxygen on migration of cancer cells on an integrated microfluidic device [30]. The Caski cells showed slower migration rate under $15 \%$ of oxygen than that under $5 \%$ oxygen. The impact of shear stress is mainly discussed on vascularized tissues or mammary ducts. For example, fluid shear stress was indicated to mediate endothelial cell transcription, proliferation, barrier function, and changes in
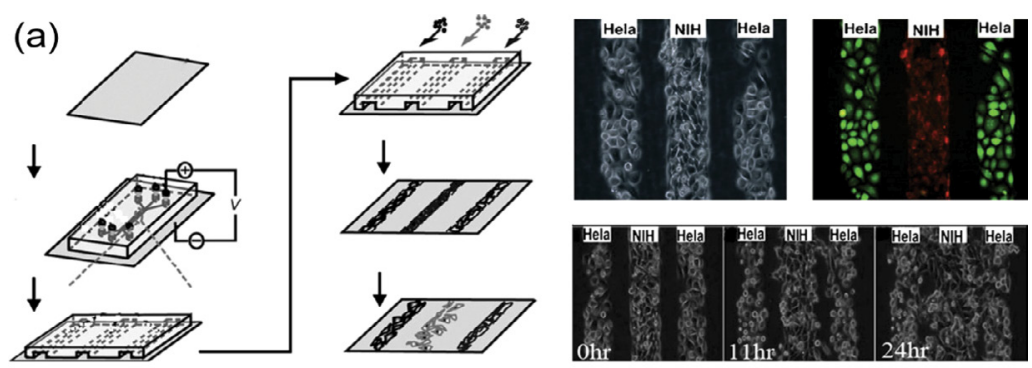

(b)
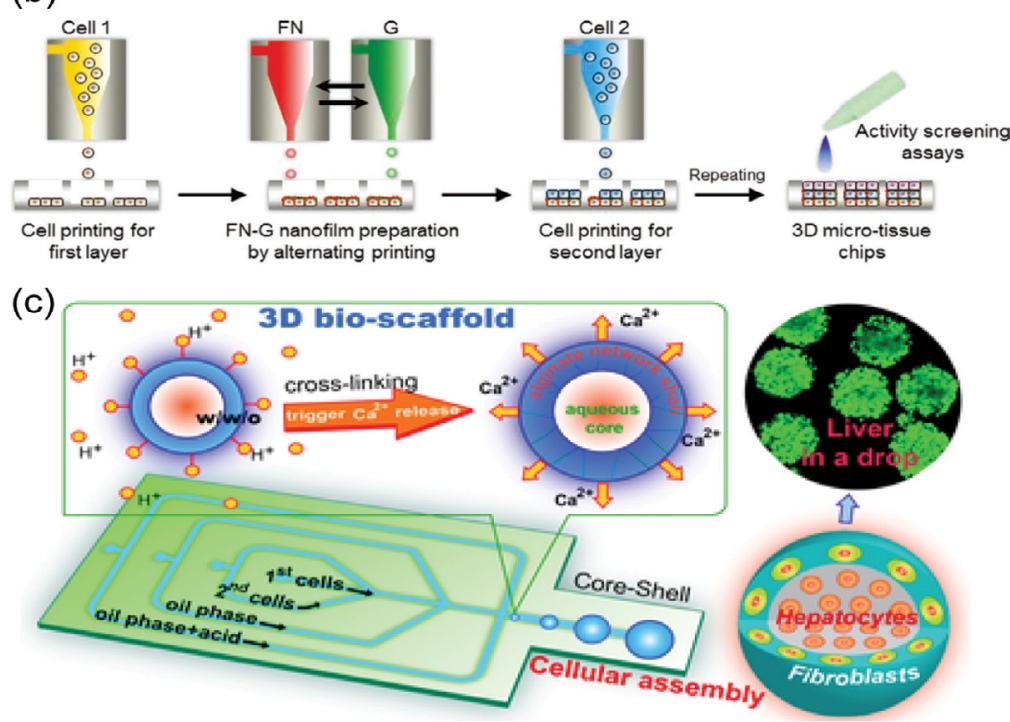

Figure 1: Cell patterning forms. (a) Cells patterning via electrochemical control [8]. (b) 3D micro-tissue arrays by printing of single cells and proteins [9]. (c) Controlled assembly of heterotypic cells in a core-shell scaffold [10]. 
actin cytoskeleton rearrangement. Various microfliuidic devices have been developed to control the shear stress applied on cells. The two-independent-channel types, which separated by a gel/scaffold compartment, has been used often to control [31] or study the influence of shear stress on cultured cells. The microfluidics shows advantages for allowing the flow to be controlled precisely in the channels as well as across the gel compartment [32,33]. Both micro environmental components and intricate architecture of the micro-vasculature networks strongly influence the fluid shear stress.

The influence of shear stress can be limited by separating the cells from the flow with a barrier, such as hydrogels [27-29], nano porous membranes [30], and micro channels [28], that allow passive diffusion of biomolecules.

Temperature also affects cellular behavior. To study the impact of temperature on microfluidic systems, perfuse temperature-controlled liquid were introduced into the systems. The control of temperature is realized by two distinct laminar-flow-based systems [38,39]. This approach has been applied on revealing the dependence of temperature for development rate of embryo [38]. Similar successful application was achieved activating or deactivating temperature sensitive genes in cytoskeletal dynamics study [33].

We have reviewed the types of microfluidic culture in previous work [27]. And due to the spatial constraints of micro channels, twodimension (2D) culture show dominance of diffusion over convection. This feature of mass transport also controls the transport of signaling molecules in $3 \mathrm{D}$ micro systems but is governed mostly through the external cellular matrix (ECM).

The in vivo microenvironment is a confined space for cells to live. The confinement has impact on cell structure and behavior. Compared to single channel, micro-compartmentalization devices are more capable to rebuild this confinement, especially for physical confinement encountered by cells during migration and invasion, creating in vivolike cellular arrangements [17,41].

Traditional cell migration or invasion studies are conducted in a vertical device, which hinders the real-time monitoring. However, microfluidic devices allows horizontal arrangement of compartments for better monitoring of changes in cells and the ECM during migration, therefore are more, suitable for analysis on dynamic cell transition. There are several successful reports about cell motility, for example, study the regulation of dendritic cell migration [42]. Researchers have found that mechanical confinement itself has impact on cell motility [43].

Gradient of chemical factors: Chemical concentration gradients are regulated to control many basic cell functions and biological processes such as gene regulation (MAPK-mediated bimodal gene expression and adaptive gradient sensing in yeast), cancer metastasis [44,45] cellular chemotaxis [37,46] and migration [47,48], differentiation, development $[49,50]$, immune response [51,52], wound healing $[53,54]$ and embryogenesis [55].

Early in vitro platforms to study the effect of chemical gradient, like Boyden chamber [50], Dunn slide chamber [57], Zigmond chamber [58] and agarose/petri dish [59], are limited to reach the length scales that are actually relevant to biological cells. Microfluidic device overcomes these shortages and offers higher gradient resolutions and provides well-controlled hydrodynamic and mass transport conditions. The temporal and spatial control over defined gradients of soluble factors or immobilized factors (on surfaces) provided by flow-based microfluidic devices is a significant improvement over the widely available methods. The effect of flow alone on neutrophils has been addressed and mechanical activation by shear from laminar flow in micro channels was demonstrated [60].

Cell-cell and cell-extracellular matrix (ECM) interactions: Cellcell interaction is realized by cell-cell junctions or paracrine signaling mechanisms, and determines the response to stimuli and cellular phenotypes. Microfluidics offers opportunity to isolate specific signals at single cell level and obtain a clear understanding of genotypic and phenotypic variation among similar cell type by high-throughput screening. By directing interactions between cell surfaces, specific homotypic or heterotypic cell-cell interactions can be studied. [61,62].

Generally, seeding of different types of cells is the first step for cellcell interaction study. Unlike 2D culture, 3D culture model typically needs to premix cells with matrix (Figure 2a). The 3D structure provides the foundation of human complex tissue network and is proper to serve as a study model in microfluidics. Other designs of chips for cell-cell interactions include microvalves, microchannels and membrane as shown in reference [63-68] (Figure 2b-d) and to control administration of metabolites from one kind of cells to the receptor cells, our group had once presented a so called surface tension plug on a microfluidic device. Based on this device, we investigated the signal pathway between 293 and L-02 cells [69]. Paracrine communication is usually studied on a two-channel type that separated by a gel channel or intervening gel. In this model, interstitial flow application induced 3D tissue-like structures, which proved the enhancement of cell-cell cohesion. [70].

Li's group used electrochemical desorption of self-assembled monolayers (SAMs) to control multiple types of adherent cells in their migration behaviors in real time [8]. The first electrochemical desorption of SAMs in fibronectin filled PDMS channels induces the adhesion of cells in the channels. After the PDMS stamp was peeled off, a separation of different types of cells without physical barriers was formed. Then a second step is desorption releases the remaining SAMs and enables cells to spread freely.

The composition and physical features of ECM directly influence a range of cellular processes including cell life/death, differentiation, shape, polarization, and motility [71-75]. Therefore, the ECM surrounding cells is critical to determine the cell fate. Various ECM materials have been used including naturally-derived polymers (collagen, hyaluronan and fibrin) and artificial polymers (alginate, polyethylene glycol (PEG), and poly (lactic-co-glycolic) acid (PLGA)) Naturally-derived ECM materials are biocompatible but limited in cost and repeatability, while artificial polymers are readily controllable in architecture, stiffness, porosity and shape. Fischbach's group had reported the use of arginylglycylaspartic acid (RGD)-peptide that incorporated into a 3D alginate ECM, which increased angiogenic activity of cancer cells [76].

Laminar-flow microfluidics is an attractive approach to generate a linear gradient using small amounts of molecules, and thus is suitable for conducting studies on specific cell-ECM interactions (Figure 3) $[12,78]$. For example, Dertinger showed microfluidic application on haptotaxis study based on a T-sensor network, and analysis showed that the surface density of laminin oriented axon specification. Hsu used a parallel flow chamber to study the influence of shear stress and investigate the interactions between haptotaxis and shear stress during EC migration. In 3D microfluidic vessel model, luminal combined with interstial flow are major factors to regulate cell-cell and cell-ECM signaling. The interstial flow is the extracellular fluid that exists in the interstitial spaces between tissue spaces, can direct the migration of cancer cells [79] (Figure 4). 
(a)
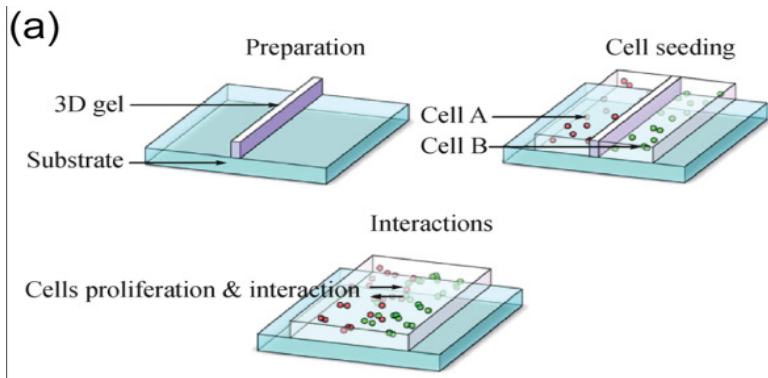

(c)
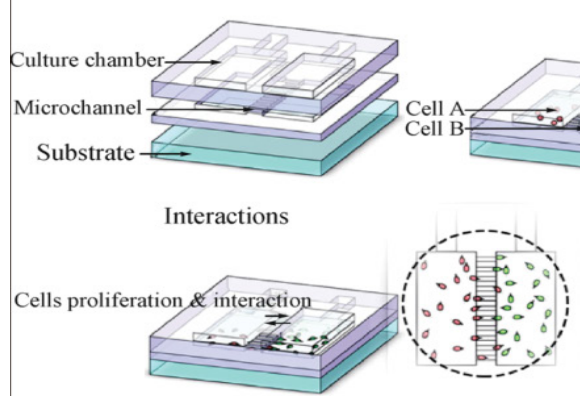

Cell seeding

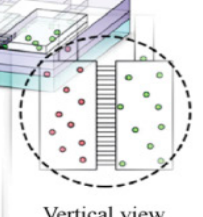

Vertical view (b)

Chip design

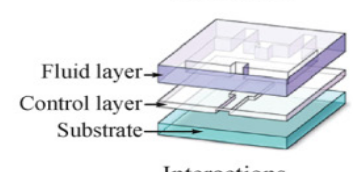

Interactions

Cells proliferation \& interaction

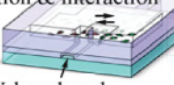

Valve closed

(d)
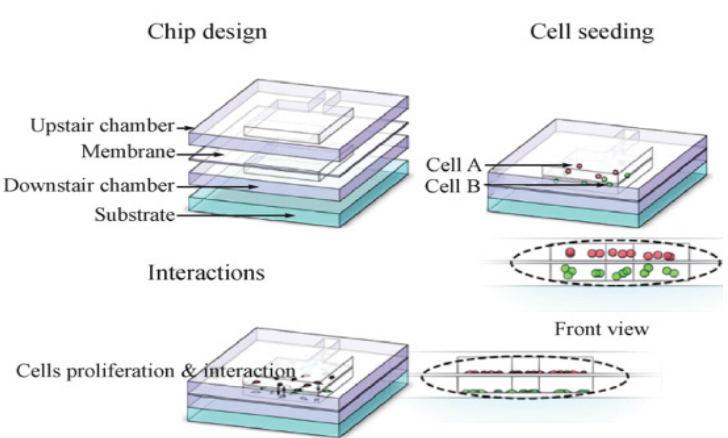

Figure 2: Common designs and features of the chips for cell-cell interactions. (a) Typical progress of seeding and culturing cells in 3D structure. (b) Pneumatic micro valve operations for cell co-culture. (c) Micro channel design for real time observation of cell-cell interaction. (d) Membrane insertion between two chambers for separating and culturing cells. Adapted from [68].

(a) Laminar flow process for loading device

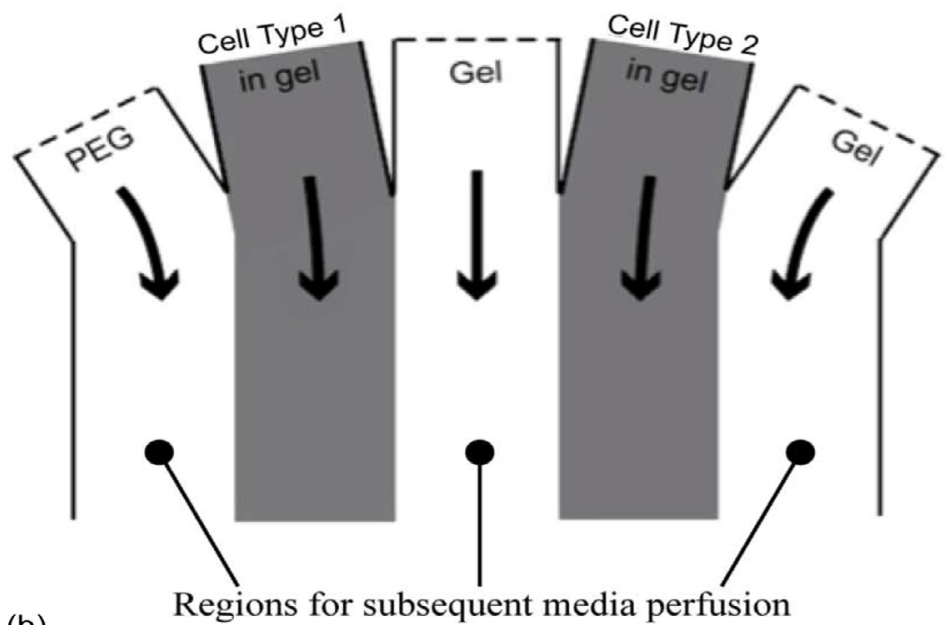

(b)

\section{Laminar Flow Patterning}
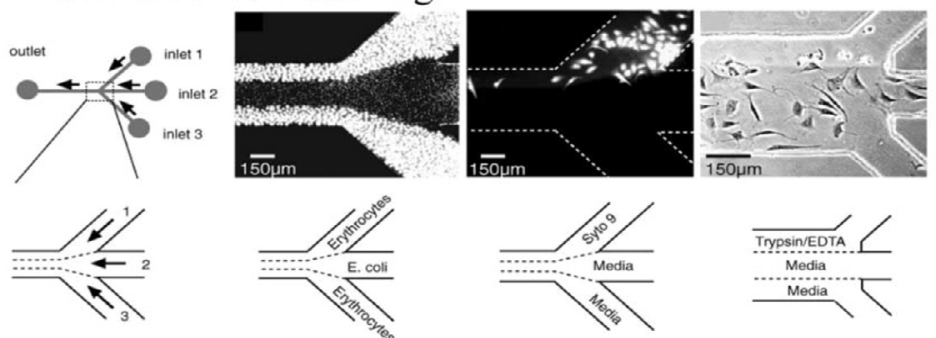

Figure 3: Laminar-flow control by microfluidics. (a) A device used for partitioning a mirofluidic channel using gels to enable tunable 3D cell culture. Separation is achieved with laminar flow using a syringe pump [41]. (b) Patterning of cells using laminar flow [77]. 
A

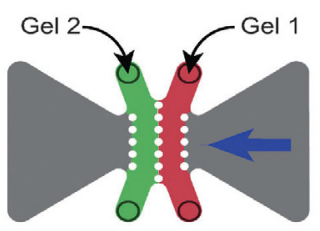

C

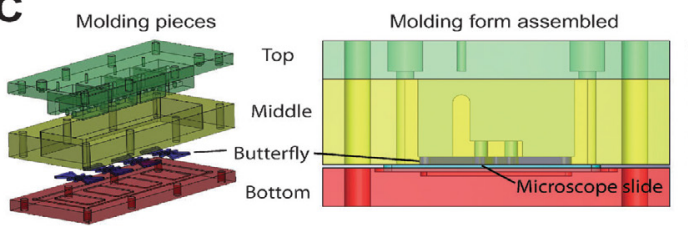

Molding form top view

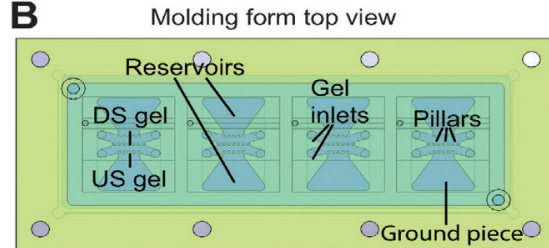

Cross section

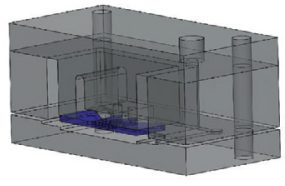

D
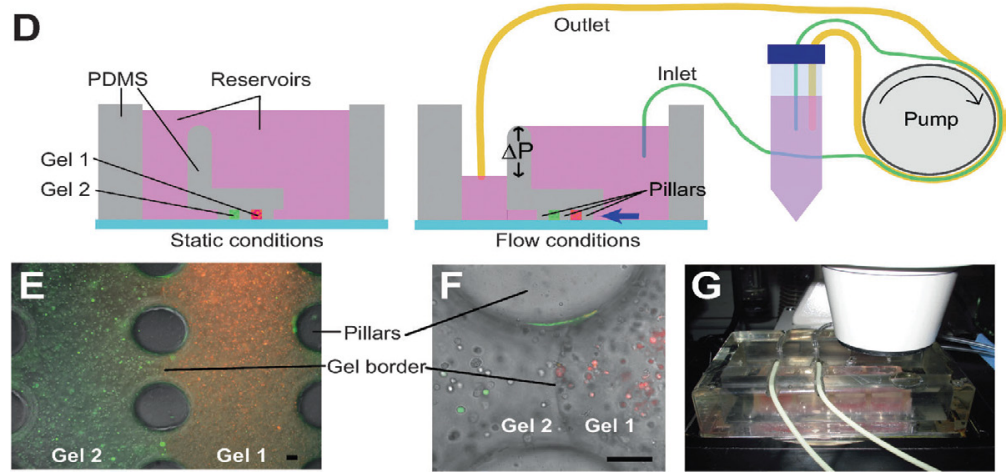

Figure 4: Injection molding allows easy and robust set up of 4 parallel experiments on a conventional scope. (A) A single unit containing two gel compartments (upstream (US) and downstream (DS)) and medium reservoirs with different pressure heads that drive flow. (B) Top view of device shows four units on one slide, allowing parallel experimentation with a motorized microscope stage. (C) Flow chamber modules consisting of top, middle and bottom part defining the reservoirs and the butterfly-shaped ground piece creating gel channels in different perspectives as labelled. (D) Schematic of flow setup. For static conditions (left), both reservoirs are filled to the top; for flow conditions, a pressure head of $7 \mathrm{~mm} \mathrm{H} O$ is maintained throughout the experiment with a peristaltic pump setup as shown. (E) Fluorescence microscopy image overlaid with phase of the interface between two fluorescently-labeled cell-loaded gels confined by PDMS pillars. (F) Close-up of E showing the gel border. (G) Chamber setup with tubing casket on an inverted microscope. Scale bars: 100 m. Details can be found in [79].

(a)

(b)
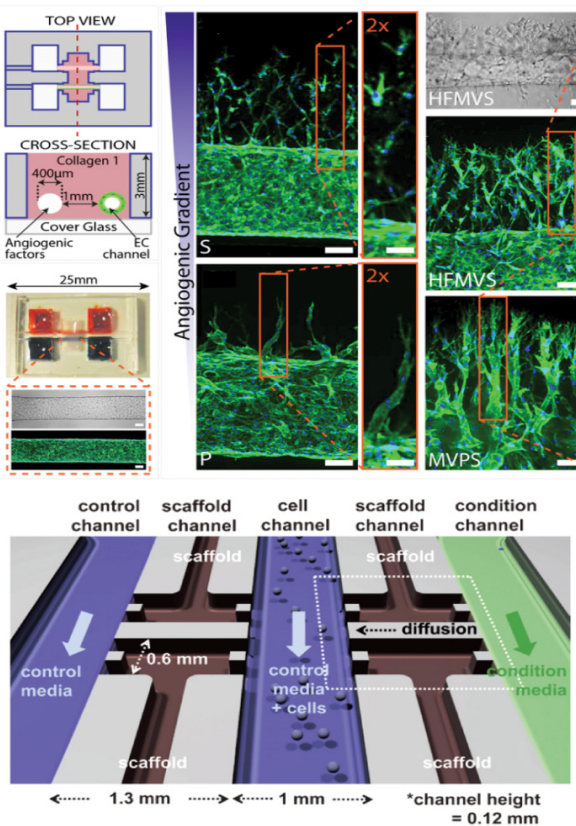

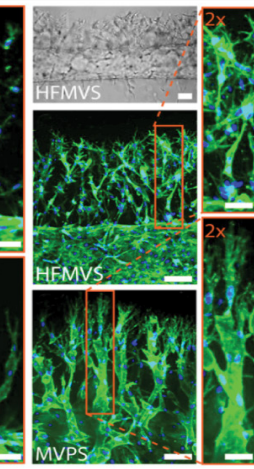

(c) 3D view

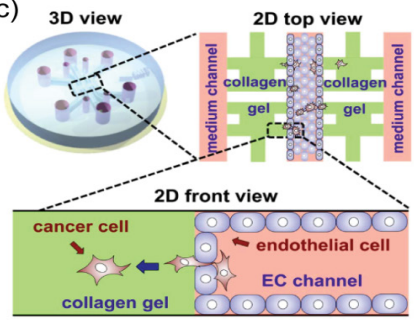

Figure 5: Microfluidic 3D cancer models. (a) Three-dimensional formation of endothelial sprouts and neovessels in a microfluidic device [80]. (b) Schematic for microfluidic cell migration assay enabling direct comparison of cell migration behavior between the condition and control sides [81]. (c) Microfluidic system of tumor cell extravasation [82]. 


\section{Microfluidic applications in cell biology}

Bio-microfluidics has been successfully been applied in cellular biology for study various cellular behaviors and phenotypes including cell growth, differentiation, signal transduction, protein secretion and transport, gene expression, cell and ECM behaviors, and cytoskeletal dynamics.

Microfluidic 3D cancer models: a) Angiogenesis and metastasis: With the development of biomaterials, several chip-based models have provided information and data about cancer-related processes, such as angiogenesis, migration and extravasation (Figure 5). Angiogenesis comprises of endothelial sprouting and intussusceptive micro vascular growth, which is remodeling of existing vascular networks by forming a new vessel from an existing one. This process can be driven by growth factors, like vascular endothelial growth factor (VEGF) gradients, hypoxic conditions and the presence of tumors or trans endothelial flow. Angiogenesis is crucial to include in cancer models, because it is a prerequisite for tumor growth, invasion, progression, and metastasis. One strategy to build vascular models is to separate two parallel microfluidic channels by a hydrogel filled channel in the middle [80]. The other way is the vascular structures fully embedded within 3D ECM [83]. As an example of the second approach, endothelial colonyforming-derived endothelial cells and normal human lung fibroblasts are mixed with fibrin matrix [84]. Angiogenesis-based approaches were successfully employed in microfluidic devices to exploit paracrine and juxtacrine signaling between ECs and MSCs [75] or between ECs and fibroblasts to generate vascular networks [86]. It had been reported that EC and MSC co-cultures were employed to vascularize cell spheroids for therapeutic neovascularization [87].

Metastasis is a complex process in cancer started with intravasion, invasion of cancer cells through the basal membrane into a blood or lymphatic vessel, followed by extravasion, entrance in other tissues and/or organs $[16,88]$. Chip-based models had been developed for intravasion and extravasion processes, in which the formation of an endothelial monolayer on a $3 \mathrm{D}$ collagen type I hydrogel mimicking ECM enabled the precise quantification and control of critical microenvironmental factors.

b) Drug discovery on tissue or organ level: One of the successful practical applications of $3 \mathrm{D}$ cancer systems is in the drug discovery, especially for the screening of drug toxicity. Animal models are limited for difference in metabolism and cellular response to chemical signals from that in humans [89]. The 3D cancer systems provide a more humanized platform that may enhance the predictability of new drug in humans $[90,91]$. Multiple parameters in 3D microenvironment, which strongly affects the drug effect, require a more complex in vitro model to investigate at tissue or organ level.

Continued development and integration of microtechnology with 3D cancer biology support the generation of $3 \mathrm{D}$ in vitro cancer models at tissue level. The microminiaturization fabrication enables hollow shaped, or duct-like, structures, which are compatible with mammary duct and blood vessels. Nelson [92] created 3D mouse mammary ducts by micropatterning of collagen gel to investigate the effect of transformation growth factor-beta on mammary branching morphogenesis. They demonstrated the important role of tissue geometry during organ morphogenesis and its role in defining the local cellular microenvironment. However, this model lacks in introducing continuous flow. Other examples for duct-like structures that use microchannel geometry, gel patterning, fluid dynamics, or microfiber generation overcome this problem [83]. Bischel constructed a circular shaped lumen system after lining the lumen with endothelial cells. By a viscous fingering method, a less viscous solution tunnels through the center of a more viscous solution can be created [93,94]. organson-chips (also known as organ-on-a-chip) is microfluidic device for culturing living cells in continuously perfused, micrometer sized chambers in order to model physiological functions of tissues and organs.

The word chip in organ-on-chip stems from the original fabrication

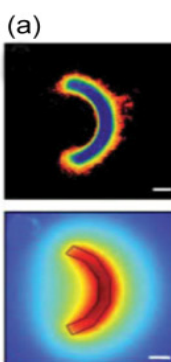

(b)
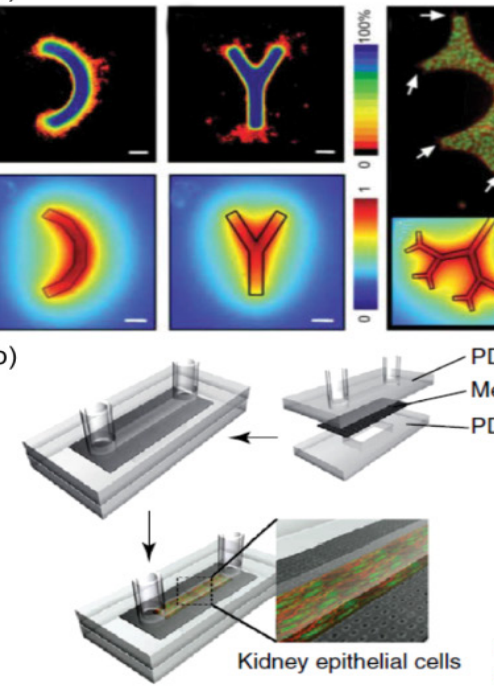

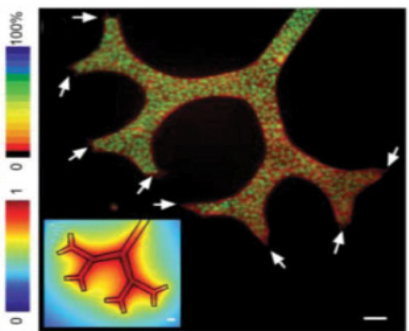

PDMS channel Membrane PDMS well

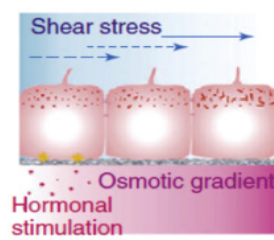

(c)
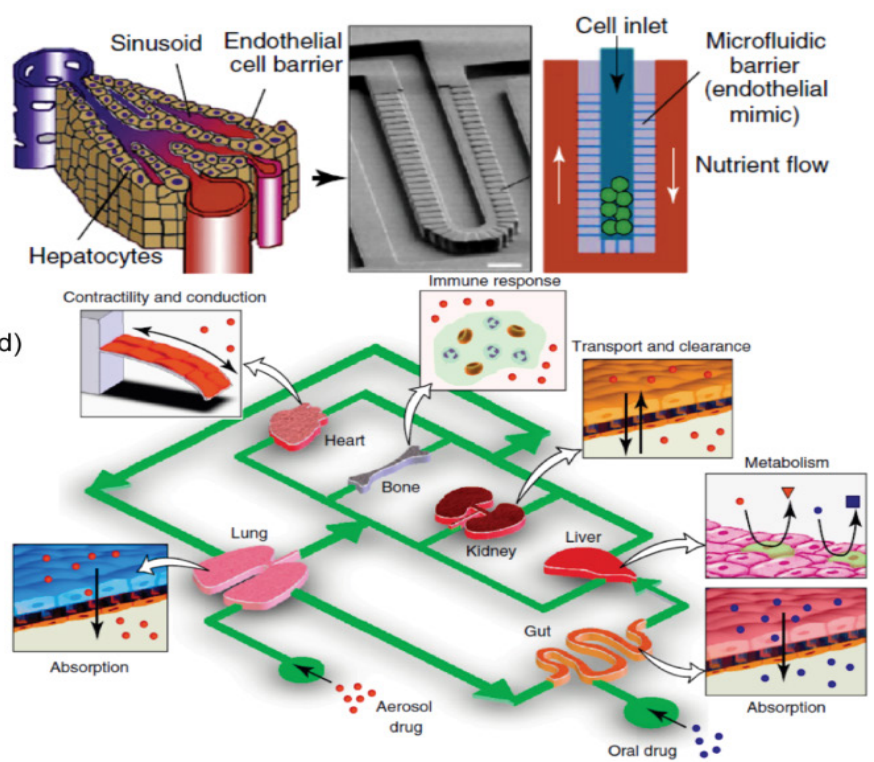

Figure 6: Microengineered tissues or organs on chips. (a) Branching position is determined by tubule geometry and is consistent with the concentration profile of secreted diffusible inhibitor(s) [92]. (b) A microfluidic kidney epithelium model [95]. (c) Liver-on-a-chip [96]. (d) The human-on-a-chip concept [4]. 
method, a modified form of photolithographic etching used to manufacture computer microchips, which allows control of surface feature shapes and sizes on the same scale (nm to $\mu \mathrm{m}$ ) that living cells sense and respond to in their natural tissue milieu. The simplest system is a single, perfused microfluidic chamber containing one kind of cultured cells that exhibits functions of one tissue type. In more complex designs, two or more micro channels are connected by porous membranes, lined on opposite sides by different cell types, to recreate interfaces between different tissues. Development of these micro engineering approaches has opened entirely new possibilities to create in vitro models that reconstitute more complex $3 \mathrm{D}$ organ level structures and to integrate crucial dynamic mechanical cues as well as chemical signals. There have been different kinds of tissue or organ chip models for specific research (Figure 6), such as liver-on-a-chip, [96] kidney-on-a-chip, [97,98] gut-on-a-chip, [99,100] lung-on-a-chip, $[101,102]$ heart-on-a-chip [103] and vessel-on-a-chip [104]

The integration of functional organ mimetics, such as gut-, liver-, lung- and skin-on-chip within a "human-on-a-chip" (Figure 6d), could provides improved methods to explore different routes of drug delivery (oral, aerosol and transdermal), as well as their effects on the efficacy or toxicity of different drug formulations [4].

Recently, a new platform has been developed called the tumormicroenvironment-on-a-chip (T-MOC) to mimic the complex pathophysiological transport within the tumor and surrounding microenvironment. The T-MOC system is able to precisely modulate environmental parameters such as interstitial fluid pressure and tissue microstructure to analyze the significant effects such as each parameter dictates on nanoparticle and drug transport [105,106]. Similar to T-MOC, there is organ-tumor-on-a-chip. Organ-tumor-on-a-chip refers to modeling of tumors on microfluidic chips, and the resulting organ-on-a-chip type human cancer models can be used for research on cancer growth and metastasis, drug target discovery, testing drug compounds, and for associated companion diagnostics. Investigations have been made recently on tumor-on-a-chip for the tumor of lung, bone marrow, brain, breast, urinary system (kidney, bladder and prostate), intestine and liver [107].

Microfluidic organs-on-chips research must also contend with specific technical challenges. Fabrication requires specialized microengineering capabilities. Bubbles in microfluidic channels may injure cells and hamper fabrication and control of chips, and it can be difficult to completely remove them. Although continuous perfusion generally supports high levels of long-term cell survival, the use of simplified ECM gels or thin ECM coatings can be a problem owing to matrix degradation or contraction over time. Additional challenges include achieving robust and consistent cell seeding in microfluidic channels, preventing microbial contamination, and controlling the cell-cell and cell-ECM interactions necessary to generate precise tissue structurefunction relationships. Even with these limitations, microfluidic culture devices have much to offer. In organs-on-chips, cell types of one tissue can be positioned precisely and consistently relative to those of another. Another advantage of organs-on-chips is the ability to control fluid flow, which enhances the differentiation, function and long-term survival of many cell types. For example, human lung cells have been cultured on chip in a functional state for at least one month in culture [108]. The true power of microsystems engineering lies in the ability to design synthetic culture systems in which many different control parameters (e.g., types and positions of cells; precise 3D orientation of tissue-tissue interfaces; transcellular chemical, molecular and oxygen gradients; flow levels and patterns; mechanical forcing regimens) can be changed independently, while simultaneously carry out high resolution and real-time imaging of molecular-scale events within a 3D tissue or organ context.

Although bioengineered 3D microsystems and organ-on-a-chip technologies are relatively new and still require further validation and characterization, their potential to predict clinical responses in humans could have profound effects on drug discovery and environmental toxicology testing. The scale-up of these complex technologies, together with systems integration of the engineering (e.g. fluidics handling, pumps) into easy to use, scalable, reproducible and user-friendly systems will be the key to their future success. It will be important to ensure that appropriate biomarkers and assays are developed for use with these microsystems, and to validate the extrapolation of in vitro results to the human situation.

Microfluidic devices for cell-based assays have provided new types of microenvironments and new methods for controlling and observing the cellular responses. As more microfluidic devices for cell biology are developed and implemented to address the current roadblocks such as ease of use, biological validity, and limitations in readouts, the unique strengths of these devices will become more accessible to the general biology community as common laboratory tools.

\section{Stem cell biology}

Stem cells in vivo are established in niche, which is the microenvironment stem cells lived in and preserves stem cells from physiological stimuli. This microenvironment regulates how stem cells participate in tissue generation, maintenance, and repair. Microtechnology-based platforms enable imitation of complex physiological context, which fulfill the requirements in the area of stem cell studies.

Regulation of human stem cell differentiation: As the interplay between stem cells and their microenvironments strongly influences stem cell differentiation, microfluidic control of soluble and insoluble factors enables precisely anticipate of the cell fate. The ways to control these factors are discussed in section 2 Cell and environment control, which are similar in regulation of stem cells. In this part, we will present how these factors affect differentiation of stem cells.

Kawada presented a membrane-based microfluidic device designed to form spatiotemporally nonuniform culture environments for stem cells (Figure 7a).The soluble factors diffused through the membrane depending on flow rate. In their work, the soluble factors include RA and leukemia inhibitory factor were introduced to determine whether miPSCs expressed Nanog, a transcription factor required for selfrenewal of ESCs. The results showed that a low concentration of RA for $72 \mathrm{~h}$ induction was sufficient to suppress Nanog.

The other way to control soluble factors is to generate concentration gradient with a slow flow rate by using a simple osmotic pump. Stem cells in the chemical gradient experienced different fates [113]. Using soluble factors, Kim proposed a microplatform for on-chip differentiation of embryoid bodies [114]. They changed the duration and rate of the flow to adjust the average size of embryoid bodies, and then applied RA to induce differentiation of EBs into a neuronal lineage. The results showed that RA-treated cells appeared as mature neuronal cells with long neurites in a relatively intense response to the neuron-specific antibody TuJ1. This microsystem had been proven to be useful on-chip method to induce and monitor differentiation of EBs.

Mechanical forces like stiffness and shear stress provide a crucial set of signals to alter the structures of cells and regulate their functions, resulting in a change of differentiation. Stiffness of substrates determines the stiffness of cytoskeletons (Figure 7b). Gilbert demonstrated the 
(a)

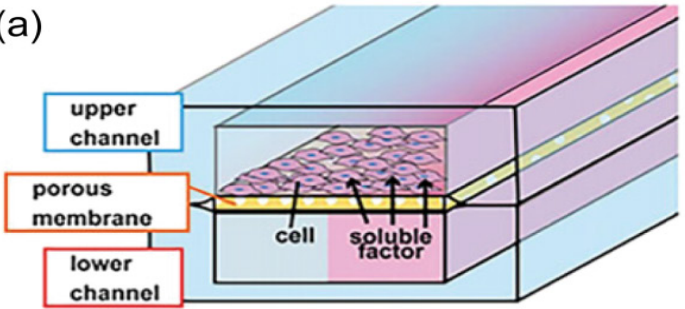

(b)

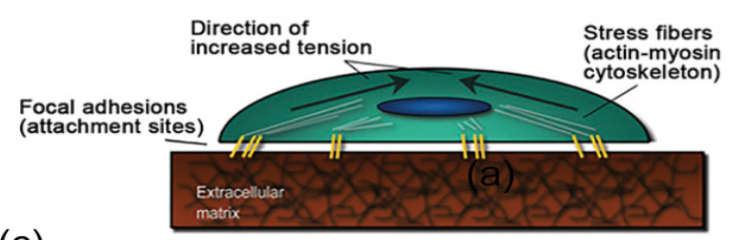

(c)

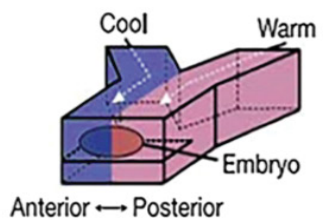

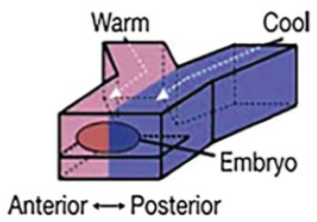

(d)

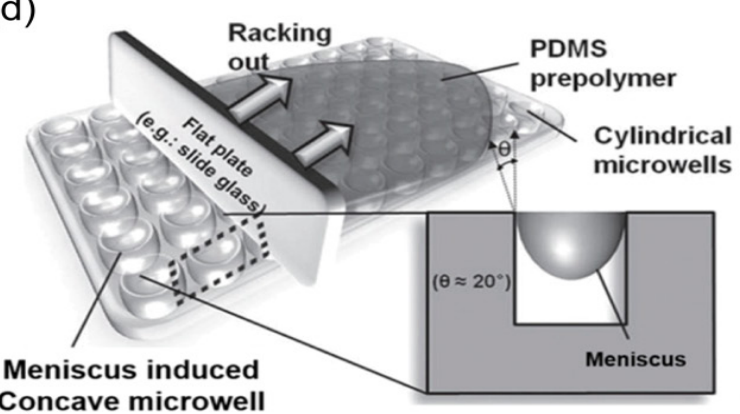

(e)

i. Inlet

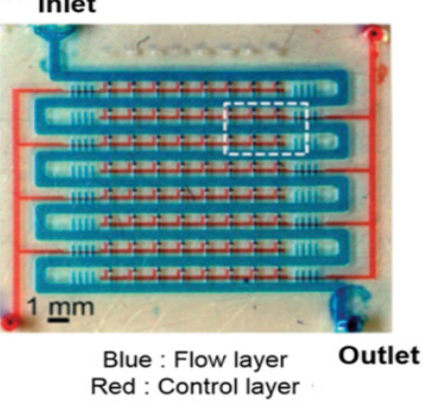

ii.

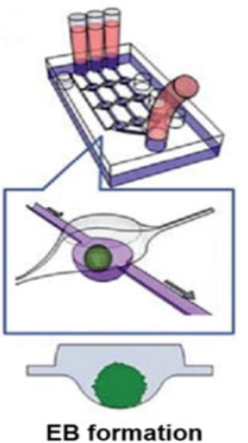

Figure 7: Microfluidic applications in stem cell biology. (a) Soluble factors are applied to stem cells as fate determinants through porous membrane [109]. (b) Physical factors applied as fate determinants include mechanical stimuli such as stiffness [100]. (c) Other factors applied as fate determinants include temperature [38]. (d) Static methods used for EB formation. (e): Dynamic methods used for embryoid body (EB) formation. (ei): Optical image of microfluidic EB trap arrays [111]. (eii): Schematic of EB formation within microwells in a multilayer microfluidic platform [112].

effect of stiffness on muscle stem cells (MuSCs) in a bioengineered microplatform, and they found that soft substrates with moduli of 12 $\mathrm{kPa}$ were observed to be better for self-renewal of MuSCs and muscle regeneration [115]. Modifying substrate stiffness is the way actually changes the interaction between cells and substrates, would also orient the differentiation of NSCs. By use of variable moduli interpenetrating polymer networks to modulate the stiffness of substrate, researchers found that moduli of approximately10 Pa blocked the differentiation, while moduli of about $500 \mathrm{~Pa}$ induced expression of the neuronal marker $\beta$-tubulin III and differentiation into glial cells with moduli of approximately 1,000-10,000 $\mathrm{Pa}$ [116].

Shear stress also plays role in regulating the differentiation. Lee controlled shear stress by micrrofluidics and found that ESCs differentiated into endothelial cells under the uniform cell docking and shear stress conditions [117]. Kim investigated the osteogenic differentiation of MSCs according to the applied shear stress through transcriptional coactivator with PDZ-binding motif (TAZ) activation using a microplatform with an osmosis-driven pump [118]. The interstitial level of shear stress induced osteogenic differentiation of MSCs, which is inherently caused by nuclear localization of TAZ.

Temperature has been used on chip to control the behaviors of stem cells by Lucchetta's group (Figure7c). They placed an embryo in a micro platform and introduced a flow with different temperature steps to the anterior and posterior halves of the embryo $[38,119]$. Temperature was shown to significantly affect the early development of the embryo. Other factors include dissolved oxygen, compressive pressure and electricity also proved to have influence on stem cell differentiation [120-122].

Before the differentiation of ESCs, the formation of embryoid bodies (EBs), three-dimensional aggregates of pluripotent stem cells, are regulated by homophilic interactions of the $\mathrm{Ca}^{2+}$-dependent cell adhesion molecule E-cadherin [123-125]. The size of the EB is a critical factor influencing the differentiation of ESCs: Large EBs tends to become part of the endoderm and mesoderm, while small EBs tend to differentiate into ectoderm tissue. There two main types of methods to control EBs. One is static, using well-defined micro wells to form EBs and to control their average size [126,127] (Figure 7d). The other way is dynamic (Figure 7e), which use microfluidics to control EB size easily and enables researches under various changes of the microenvironment [114].

Stem cell niche engineering: A 3D microfluidic culture model is required to recapitulate the native niche. There are various of microtechnologies (e.g. stop-flow lithography [128], robotic formation of micro gels [26] and droplet microfluidics). And droplet microfluidics is capable to compartmentalize cells into mono-dispersed and physic chemically defined 3D matrices, therefore, is advantageous in constructing artificial niches. Both synthetic and natural hydrogels have been utilized in creating in vitro $3 \mathrm{D}$ platforms by mixing different cells into these hydrogels in varied mechanical and biochemical gel properties. For example, Huck and colleagues tuned the content of collagen/gelatin and the degree of cross-linking to obtain microbeads with varying elasticity and biodegradability. These beads were then used to study fibro-blast invasion into matrices of different stiffness [129]. Similar studies have been processed with synthetic hydrogels. Rossow's group used hyper branched polyglycerol and PEG and controlled micro gel elasticity by the molecular weight of the PEG crosslinker and the precursor concentration. They realized encapsulation of lymphoblasts and fibroblasts within microcapsules obtained through the co-polymerization of these materials [130]. Garcia' group employed PEG-maleimide-based microgels for successful long-term cell culture, showing high viability of human MSCs, as well as insulin secretion of human pancreatic islets [131]. 3D co-culture for niche construction can 
be realized with droplet-based technology. By varying the flow rate ratio between the two cell streams, the ration between the concentrations of two cell types can be altered within the micro gel [132]. Another way to build co-culture is the layer-by-layer. Sakai and colleagues reported a first microfluidical encapsulation of rat adipose-derived cells in gelatin microbeads, and a co-encapsulated in another gelatin microbead, which supported the adhesion of L929 cells [133].

All these examples highlight the advantages of droplet microfluidics to generate cell-laden microcapsules as cell-instructive microenvironments.

\section{Conclusion}

The progress in microfluidic culture, especially the new microfluidic 3D model, elucidates questions in cell biology in a more efficient way. Because multiple key biophysical and biochemical parameters attribute to the complexity of in-vivo microenvironment and are controllable by 3D microfluidic devices.

With more vivo-like features, researches based on 3D microfluidic culture model other than 2D model may be a trend in cell biology studies to provide a greater understanding of biological mechanisms and better guide the design of more physiologically compatible systems. The recent development of 3D microfluidic culture in tissue engineering has resulted in the evolution of 3D in vitro models for cell biology studies [134]; meanwhile, it calls for the development of tissue engineering and biomaterials to maximize the utility and functionality of the models. For example, smartly designed biomaterials can be degraded by growth factors at desired rates that relevant to physiological condition or be cleaved only by specific proteases like in vivo ECM [135-137]. Several pharmaceutical companies are moving toward adapting 3D in vitro cancer models as anti-cancer drug testing tools. However, it does not mean that complex organ-level in vitro culture systems will be a dominant strategy. In studies that focus on cell interaction, relative simple models are needed to avoid multiple interferences. These models are widely used in the early stages to identify therapeutical targets or screen drug candidates. For later steps like exploration of drug toxicity, analyzing at tissue/organ levels may be necessary, because multiple parameters would affect toxicity on cells. Widespread use of the microfluidic culture systems in practice would be challenged by the limitation of reliable detection methods for high-throughput and high-content analysis. It is important to develop methods for imaging, detecting, and quantifying signals. Despite this challenge, the continued development and integration of micro fluidic culture, tissue engineering and biomaterials will bring significant contributions toward a deeper understanding of mechanism in cell biology.

\section{Acknowledgement}

This work was financially supported by National Natural Science Foundation of China (Nos. 21435002, 81373373, 21621003) and CERS-China Equipment and Education Resources System (No. CERS-1-75).

\section{References}

1. Hsiao AY, Torisawa YS, Tung YC, Sud S, Taichman RS, et al. (2009) Microfluidic system for formation of $\mathrm{PC}-3$ prostate cancer co-culture spheroids. Biomaterials 30: 3020-3027.

2. Ekert JE, Johnson K, Strake B, Pardinas J, Jarantow S, et al. (2014) Threedimensional lung tumor microenvironment modulates therapeutic compound responsiveness in vitro-implication for drug development. PloS One 9: e92248.

3. Elliott NT, Yuan F (2011) A review of three-dimensional in vitro tissue models for drug discovery and transport studies. J. Pharm. Sci. 100: 59-74.

4. Huh D, Hamilton GA, Ingber DE (2011) From 3D cell culture to organs-on-chips. Trends Cell Biol 21: 745-754.
5. Yum K, Hong SG, Healy KE, Lee LP (2014) Physiologically relevant organs on chips. Biotechnol J 9: 16-27.

6. Stevens KR, Ungrin MD, Schwartz RE, Ng S, Carvalho B, et al. (2013) InVERT molding for scalable control of tissue microarchitecture. Nat Commun 4: 1847.

7. Sung KE, Beebe DJ (2014) Microfluidic 3D models of cancer. Adv Drug Deliv Rev 79-80: 68-78.

8. Li Y, Yuan B, Ji H, Han D, Chen S, et al. (2007) A Method for Patterning Multiple Types of Cells by Using Electrochemical Desorption of Self-Assembled Monolayers within Microfluidic Channels. Angew Chem Int Ed Engl 119: 1112 1114.

9. Matsusaki M, Sakaue K, Kadowaki K, Akashi M (2013) Three-Dimensional Human Tissue Chips Fabricated by Rapid and Automatic Inkjet Cell Printing. Adv. Healthc. Mater 2: 534-539.

10. Chen Q, Utech S, Chen D, Prodanovic R, Lin JM, et al. (2016) Controlled assembly of heterotypic cells in a core-shell scaffold: organ in a droplet. Lab Chip 16: 1346-1349.

11. Chen CS, Mrksich M, Huang S, Whitesides GM, Ingber DE, et al. (1997) Geometric control of cell life and death. Science 276: 1425-1428.

12. Dertinger SK, Jiang X, Li Z, Murthy VN, Whitesides GM, et al. (2002) Gradients of substrate-bound laminin orient axonal specification of neurons. PNAS USA 99: 12542-12547.

13. Wu J, Wang S, Chen Q, Jiang H, Liang S, et al. (2015) Cell-patterned glass spray for direct drug assay using mass spectrometry, Anal Chim Acta 892: 132139.

14. Jiang X, Takayama S, Qian X, Ostuni E, Wu H, et al. (2001) Controlling mammalian cell spreading and cytoskeletal arrangement with conveniently fabricated continuous wavy features on poly (dimethylsiloxane). Langmuir 18: 3273-3280.

15. Wu J, Chen Q, Liu W, Zhang Y,Lin JM (2012) Cytotoxicity of quantum dots assay on a microfluidic $3 \mathrm{D}$-culture device based on modeling diffusion process between blood vessels and tissues, Lab Chip 12: 3474-3480.

16. Zervantonakis K, Hughes-Alford SK, Charest JL, Condeelis JS, Gertler FB, et al. Three-dimensional microfluidic model for tumor cell intravasation and endothelial barrier function. PNAS USA 109:13515-13520.

17. Sung KE, Yang N, Pehlke C, Keely PJ, Eliceiri KW, et al. (2011) Transition to invasion in breast cancer: a microfluidic in vitro model enables examination of spatial and temporal effects. Integr. Biol. UK 3:439-450.

18. Wu J, Chen Q, Liu W, Lin JM (2013) A simple and versatile microfluidic cell density gradient generator for quantum dot cytotoxicity assay, Lab Chip 13 1948-1954.

19. Wu J, Li H, Chen Q, Lin X, Liu W, et al. (2014) Statistical single-cell analysis of cell cycle-dependent quantum dot cytotoxicity and cellular uptake using a microfluidic system, RSC Adv. 4: 24929-24934.

20. Chen Q, Wu J, Zhang Y, Lin Z, Lin JM (2012) Targeted isolation and analysis of single tumor cells with aptamer-encoded microwell array on microfluidic device, Lab Chip 12: 5180-5185.

21. Chen F, Lin L, Zhang J, He Z, Uchiyama K, et al. (2016) Single-Cell Analysis Using Drop-on-Demand Inkjet Printing and Probe Electrospray lonization Mass Spectrometry, Anal Chem 88: 4354-4360.

22. Zhang J, Chen F, He Z, Ma Y, Uchiyama K, et al. (2016) A novel approach for precisely controlled multiple cell patterning in microfluidic chips by inkjet printing and the detection of drug metabolism and diffusion, Analyst 141: 29402947.

23. Pepper ME, Parzel CA, Burg T, Boland T, Burg KJ, et al. (2009) Design and implementation of a two-dimensional inkjet bio printer. Annual International Conference of the IEEE Engineering in Medicine and Biology Society, IEEE.

24. Moon S, Hasan SK, Song YS, Xu F, Keles HO, et al. (2009) Layer by layer three-dimensional tissue epitaxy by cell-laden hydrogel droplets. Tissue Engineering Part C-Methods 16: 157-166.

25. Rizvi Celli JP, Xu F, Evans CL, Abu-Yousif AO, Muzikansky A, at al. (2011) Biologically relevant $3 D$ tumor arrays: treatment response and the importance of stromal partners. SPIE BiOS, International Society for Optics and Photonics.

26. Dolatshahi-Pirouz, Nikkhah M, Gaharwar AK, Hashmi B, Guermani E, et al. (2014) A combinatorial cell-laden gel microarray for inducing osteogenic differentiation of human mesenchymal stem cells. Sci. Rep. 4:3896. 
27. Gao D, Liu H, Jiang Lin JM (2012) Recent developments in microfluidic devices for in vitro cell culture for cell-biology research. Trends Anal. Chem. 35:150 164

28. Anders M, Hansen R, Ding RX, Rauen K, Bissell Korn WM (2003) Disruption of $3 \mathrm{D}$ tissue integrity facilitates adenovirus infection by deregulating the coxsackievirus and adenovirus receptor. PNAS USA 100: 1943-1948.

29. Kievit FM, Florczyk SJ, Leung MC, Veiseh O, Park JO, et al. (2010) Chitosanalginate $3 \mathrm{D}$ scaffolds as a mimic of the glioma tumor microenvironment. Biomaterials 31: 5903-5910.

30. Lin X, Chen Q, Liu W, Zhang J, Wang S, et al. (2015) Oxygen-induced cell migration and on-line monitoring biomarkers modulation of cervical cancers on a microfluidic system. Sci Rep 5: 9643.

31. Vickerman V, Blundo J, Chung SKamm R (2008) Design, fabrication and implementation of a novel multi-parameter control microfluidic platform for three-dimensional cell culture and real-time imaging. Lab Chip 8:1468-1477.

32. Mack PJ, Zhang Y, Chung S, Vickerman V, Kamm RD, et al.(2009) Biomechanical regulation of endothelium-dependent events critical for adaptive remodeling. J. Biol. Chem. 284: 8412-8420.

33. Song JW, Munn LL (2011) Fluid forces control endothelial sprouting. PNAS 108: $15342-15347$

34. Mosadegh B, Huang C, Park JW, Shin HS, Chung BG, et al. (2007) Generation of stable complex gradients across two-dimensional surfaces and threedimensional gels. Langmuir 23:10910-10912.

35. Saadi W, Rhee SW, Lin F, Vahidi B, Chung BG, et al. (2007) Generation of stable concentration gradients in $2 \mathrm{D}$ and $3 \mathrm{D}$ environments using a microfluidic ladder chamber. Biomed Microdevices 9: 627-635.

36. Wu H, Huang B, Zare RN (2006) Generation of complex, static solution gradients in microfluidic channels. J Am Chem Soc 128: 4194-4195.

37. Abhyankar VV, Lokuta MA, Huttenlocher A, Beebe DJ (2006) Characterization of a membrane-based gradient generator for use in cell-signaling studies. Lab Chip 6: 389-393.

38. Lucchetta EM, Lee JH, Fu LA, Patel NH (2005) Ismagilov RF Dynamics of Drosophila embryonic patterning network perturbed in space and time using microfluidics. Nature 434:1134-1138.

39. Pearce TM, Wilson JA, Oakes SG, Chiu SY (2005) Integrated microelectrode array and microfluidics for temperature clamp of sensory neurons in culture. Lab Chip 5: 97-101.

40. Velve-Casquillas G, Costa J, Carlier-Grynkorn F, Mayeux A Tran PT (2010) A fast microfluidic temperature control device for studying microtubule dynamics in fission yeast Method. Cell Biol. 97:185-201.

41. Wong P, Perez-Castillejos R, Love JC, Whitesides GM (2008) Partitioning microfluidic channels with hydrogel to construct tunable $3-D$ cellular microenvironments. Biomaterials 29:1853-1861.

42. Faure-André G, Vargas P, Yuseff MI, Heuzé M, Diaz J, et al. (2008) Regulation of dendritic cell migration by $\mathrm{CD} 74$, the MHC class II-associated invarian chain. Science (New York, N.Y.) 322:1705-1710.

43. IrimiaToner MD (2009) Spontaneous migration of cancer cells under conditions of mechanical confinement. Integr. Bio I: 506-512.

44. Wang SJ, Saadi W, Lin F, Minh-Canh Nguyen C, et al. (2004) Differential effects of EGF gradient profiles on MDA-MB-231 breast cancer cell chemotaxis. Exp Cell Res 300: 180-189.

45. Nandagopal S, Wu D, Lin F (2011) Combinatorial guidance by CCR7 ligands for T lymphocytes migration in co-existing chemokine fields. PLoS One 6: e18183.

46. Jeon NL, Baskaran H, Dertinger SK, Whitesides GM, Van De Water L Toner M (2002) Neutrophil chemotaxis in linear and complex gradients of interleukin-8 formed in a microfabricated device. Nat. Biotechnol 20: 826-830.

47. Barkefors, Le Jan S, Jakobsson L, Hejll E, Carlson G, et al. (2008) Endothelial cell migration in stable gradients of vascular endothelial growth factor a and fibroblast growth factor 2 effects on chemotaxis and chemokinesis. J. Biol. Chem. 283:13905-13912.

48. Irimia D, Liu SY, Tharp WG, Samadani A, Toner M (2006) Poznansky M. C Microfluidic system for measuring neutrophil migratory responses to fast switches of chemical gradients. Lab Chip 6:191-198.

49. Park JY, Hwang CM, Lee SH, Lee SH (2007) Gradient generation by an osmotic pump and the behavior of human mesenchymal stem cells under the fetal bovine serum concentration gradient. Lab Chip 7:1673-1680.

50. Gupta K, Kim DH, Ellison D, Smith C, Kundu A, et al. (2010) Lab-on-a-chip devices as an emerging platform for stem cell biology. Lab Chip 10: 2019-2031.

51. Li GN, Liu J, Hoffman-Kim D (2008) Multi-molecular gradients of permissive and inhibitory cues direct neurite outgrowth. Ann Biomed Eng 36: 889-904.

52. Kothapalli CR, Van Veen E, De Valence S, Chung S, Zervantonakis IK, et al (2011) A high-throughput microfluidic assay to study neurite response to growth factor gradients. Lab Chip 11: 497-507.

53. Lin F (2009) A microfluidics-based method for chemoattractant gradients. Methods Enzymol 461: 333-347.

54. van der Meer AD, Vermeul K, Poot AA, Feijen J, Vermes I, et al. (2010) A microfluidic wound-healing assay for quantifying endothelial cell migration. Am J Physiol Heart Circ Physiol 298: H719-725.

55. Heo Y, Cabrera L, Bormann C, Shah C, Takayama S, et al. (2010) Dynamic microfunnel culture enhances mouse embryo development and pregnancy rates. Hum. Reprod. 25:613-622.

56. BOYDEN S (1962) The chemotactic effect of mixtures of antibody and antigen on polymorph nuclear leucocytes. J Exp Med 115: 453-466.

57. Zicha D, Dunn GA, Brown AF (1991) A new direct-viewing chemotaxis chamber J Cell Sci 99: 769-775.

58. Zigmond SH, Hirsch JG (1973) Leukocyte locomotion and chemotaxis new methods for evaluation, and demonstration of a cell-derived chemotactic factor J. Exp. Med. 137:387-410.

59. KimKim TM (2010) Diffusion-based and long-range concentration gradients of multiple chemicals for bacterial chemotaxis assays. Anal. Chem. 82: 94019409.

60. YapKamm RD B (2005) Mechanical deformation of neutrophils into narrow channels induces pseudopod projection and changes in biomechanical properties. J. Appl. Physiol. (Bethesda, Md: 98:1930-1939.

61. Huang CP, Lu J, Seon H, Lee AP, Flanagan LA, et al. (2009) Engineering microscale cellular niches for three-dimensional multicellular co-cultures. Lab Chip 9: 1740-1748.

62. Van der Meer AD, Orlova VV, Ten Dijke P, van den Berg A, Mummery $C L$ et al. (2013) Three-dimensional co-cultures of human endothelial cells and embryonic stem cell-derived pericytes inside a microfluidic device. Lab Chip 13(2013) 3562-3568.

63. Zhuang Q, Wang S, Zhang J, He Z, Li H, et al. (2016) Nephrocyte-neurocyte interaction and cellular metabolic analysis on membrane-integrated microfluidic device, Sci. China Chem 59: 243-250.

64. Gao D, Liu H, Lin JM, Wang Y, Jiang Y (2013) Characterization of drug permeability in Caco-2 monolayers by mass spectrometry on a membranebased microfluidic device, Lab Chip 13: 978-985.

65. Jie M, Li H, Lin L, Zhang J, Lin JM (2016) Integrated microfluidic system fo cell co-culture and simulation of drug metabolism, RSC Adv 6: 54564-54572.

66. Chen Q, Wu J, Zhuang Q, Lin X, Zhang J, et al. (2013) Microfluidic isolation of highly pure embryonic stem cells using feeder-separated co-culture system, Sci Rep 3: 2433

67. Wu J, Jie M, Dong X, Qi H, Lin JM (2016) Multi-channel cell co-culture for drug development based on glass microfluidic chip-mass spectrometry coupled platform, Rapid Commun Mass Spectrom 30: 80-86.

68. R Li, Lv X, Zhang X, Saeed O Deng Y (2016) Microfluidics for cell-cell interactions: A review. Front. Chem. Sci. Eng.10: 90-98.

69. Mao S, Zhang J, Li H, Lin JM (2012) Strategy for signaling molecule detection by using an integrated microfluidic device coupled with mass spectrometry to study cell-to-cell communication, Anal Chem 85: 868-876.

70. Sudo R, Chung S, Zervantonakis IK, Vickerman V, Toshimitsu Y, et al. (2009) Transport-mediated angiogenesis in 3D epithelial coculture. FASEB J 23: 2155 2164

71. Discher DE, Janmey P, Wang YL (2005) Tissue cells feel and respond to the stiffness of their substrate. Science 310: 1139-1143.

72. Discher D (2010) Matrix elasticity directs stem cell lineage specification. APS March Meeting Abstracts. 
73. McBeath R, Pirone DM, Nelson CM, Bhadriraju K, Chen CS (2004) Cell shape cytoskeletal tension, and RhoA regulate stem cell lineage commitment. Dev Cell 6: 483-495.

74. Robert J, Pelham Jr, Wang Y (1997) Cell locomotion and focal adhesions are regulated by substrate flexibility. Proc Natl Acad Sci USA 94: 13661-13665.

75. Trappmann B, Gautrot JE, Connelly JT, Strange DG, Li Y, et al. (2012) Extracellular-matrix tethering regulates stem-cell fate. Nat. Mater. 11: 642-649.

76. Fischbach C, Kong HJ, Hsiong SX, Evangelista MB, Yuen W, et al. (2009) Cancer cell angiogenic capability is regulated by $3 D$ culture and integrin engagement. PNAS USA 106: 399-404

77. Kane RS, Takayama S, Ostuni E, Ingber DE, Whitesides GM (1999) Patterning proteins and cells using soft lithography. Biomaterials 20: 2363-2376.

78. Gunawan RC, Silvestre J, Gaskins HR, Kenis PJ, Leckband DE (2006) Cell migration and polarity on microfabricated gradients of extracellular matrix proteins. Langmuir 22: 4250-4258.

79. Haessler U, Teo JC, Foretay D, Renaud P, Swartz MA (2012) Migration dynamics of breast cancer cells in a tunable 3D interstitial flow chamber. Integr Biol (Camb) 4: 401-409.

80. Nguyen DH, Stapleton SC, Yang MT, Cha SS, Choi CK, et al. (2013) Biomimetic model to reconstitute angiogenic sprouting morphogenesis in vitro. PNAS USA 110: 6712-6717.

81. Chung S, Sudo R, Mack PJ, Wan CR, Vickerman V, et al. (2009) Cell migration into scaffolds under co-culture conditions in a microfluidic platform. Lab Chip 9: 269-275.

82. Jeon JS, Zervantonakis IK, Chung S, Kamm RD, Charest JL (2013) In vitro model of tumor cell extravasation. PLoS One 8: e56910.

83. Miller JS, Stevens KR, Yang MT, Baker BM, Nguyen DHT, et al. (2012) Rapid casting of patterned vascular networks for perfusable engineered threedimensional tissues. Nat.Mater. 11: 768-774.

84. Moya M, Tran D, George SC (2013) An integrated in vitro model of perfused tumor and cardiac tissue. Stem Cell Res Ther 4 Suppl 1: S15.

85. Jeon JS, Bersini S, Whisler JA, Chen MB, Dubini G, et al. (2014) Generation of 3D functional microvascular networks with human mesenchymal stem cells in microfluidic systems. Integr. Biol. 6: 555-563

86. Kim S, Lee H, Chung M, Jeon NL (2013) Engineering of functional, perfusable 3D microvascular networks on a chip. Lab Chip 13: 1489-1500.

87. Chen DY, Wei HJ, Lin KJ, Huang CC, Wang CC, et al. (2013) Threedimensional cell aggregates composed of HUVECs and cbMSCs for therapeutic neovascularization in a mouse model of hindlimb ischemia. Biomaterials 34:1995-2004

88. Bersini S, Jeon JS, Dubini G, Arrigoni C, Chung S, et al. (2014) A microfluidic 3D in vitro model for specificity of breast cancer metastasis to bone. Biomaterials 35: 2454-2461.

89. Shuler ML, Esch MB (2010) Body-on-a chip: Using microfluidic systems to predict human responses to drugs. Pure Appl. Chem. 82: 1635-1645.

90. Cucullo L, Hossain M, Rapp E, Manders T, Marchi N, et. al (2007) Development of a humanized in vitro blood-brain barrier model to screen for brain penetration of antiepileptic drugs. Epilepsia 48:505-516.

91. Sharma SV, Haber DA, Settleman J (2010) Cell line-based platforms to evaluate the therapeutic efficacy of candidate anticancer agents. Nat. Rev. Cancer 10: 241-253.

92. CM Nelson,VanDuijn MM, Inman JL, Fletcher DA, Bissell MJ (2006)Tissue geometry determines sites of mammary branching morphogenesis in organotypic cultures. Science 314: 298-300

93. Bischel LL, Lee SH, Beebe DJ (2012) A practical method for patterning lumens through ECM hydrogels via viscous finger patterning. J Lab Autom 17: 96-103.

94. Bischel LL,Young EW, Mader BR, Beebe DJ (2013) Tubeless microfluidic angiogenesis assay with three-dimensional endothelial-lined microvessels. Biomaterials 34:1471-1477.

95. Carraro A, Hsu WM, Kulig KM, Cheung WS, Miller ML, et al (2008) In vitro analysis of a hepatic device with intrinsic microvascular-based channels. Biomed. Microdevice. 10: 795-805.

96. Lee PJ, Hung PJ, Lee LP (2007) An artificial liver sinusoid with a microfluidic endothelial-like barrier for primary hepatocyte culture. Biotechnol.Bioeng. 97: 1340-1346.
97. Zhou M, Ma H, Lin H, Qin J (2014) Induction of epithelial-to-mesenchymal transition in proximal tubular epithelial cells on microfluidic devices. Biomaterials 35(2014) 1390-1401

98. Mu X, Zheng W, Xiao L, Zhang W, Jiang X (2013) Engineering a 3D vascular network in hydrogel for mimicking a nephron. Lab Chip 13: 1612-1618.

99. Esch MB, Sung JH, Yang J, Yu C, Yu J, et al. (2012) On chip porous polymer membranes for integration of gastrointestinal tract epithelium with microfluidic 'body-on-a-chip' devices. Biomed. Microdevices 14: 895-906.

100. Imura Y, Asano Y, Sato K, Yoshimura E (2009) A microfluidic system to evaluate intestinal absorption. Anal Sci 25: 1403-1407.

101. Huh D, Fujioka H, Tung YC, Futai N, Paine R, et al. (2007) Acoustically detectable cellular-level lung injury induced by fluid mechanical stresses in microfluidic airway systems. PNAS USA 104: 18886-18891.

102. Tavana H, Zamankhan P, Christensen PJ, Grotberg JB, Takayama S, et al. (2011) Epithelium damage and protection during reopening of occluded airways in a physiologic microfluidic pulmonary airway model. Biomed. Micro devices 13: 731-742.

103. Grosberg A, Alford PW, McCain ML, Parker KK (2011) Ensembles of engineered cardiac tissues for physiological and pharmacological study: heart on a chip. Lab Chip 11: 4165-4173.

104. Nguyen DH, Stapleton SC, Yang MT, Cha SS, Choi CK, et al. (2013) Biomimetic model to reconstitute angiogenic sprouting morphogenesis in vitro. PNAS USA 110: 6712-6717.

105. Shin K, Klosterhoff BS, Han B, et al. (2016) Characterization of Cell-TypeSpecific Drug Transport and Resistance of Breast Cancers Using TumorMicroenvironment-on-Chip. Mol Pharm 13: 2214-2223.

106. Kwak B, Ozcelikkale A, Shin CS, Park K, Han B (2014) Simulation of complex transport of nanoparticles around a tumor using tumor-microenvironment-onchip. J. Control. Release 194: 157-167.

107. Kashaninejad N, Nikmaneshi MR, Moghadas $H$, Kiyoumarsi Oskouei A, ET AL. (2016) Organ-Tumor-on-a-Chip for Chemosensitivity Assay: A Critical Review. Micromachines 7:130.

108. Huh D, Matthews BD, Mammoto A, Montoya-Zavala M, Hsin HY, et al. (2010) Reconstituting organ-level lung functions on a chip. Science 328: 1662-1668.

109. Kawada J, Kimura H, Akutsu H, Sakai Y, Fujii T (2012) Spatiotemporally controlled delivery of soluble factors for stem cell differentiation. Lab Chip 12 4508-4515.

110. Wells RG (2008) The role of matrix stiffness in regulating cell behavior Hepatology 47: 1394-1400.

111. Suri S, Singh A, Nguyen AH, Bratt-Leal AM, McDevitt TC, et al. (2013) Microfluidic-based patterning of embryonic stem cells for in vitro development studies. Lab Chip 13: 4617-4624.

112. Kang E, Choi YY, Jun Y, Chung BG, Lee SH (2010) Development of a multilayer microfluidic array chip to culture and replate uniform-sized embryoid bodies without manual cell retrieval. Lab Chip 10: 2651-2654.

113. Park JY, Kim SK, Woo DH, Lee EJ, Kim JH, et al. (2009) Differentiation of neural progenitor cells in a microfluidic chip-generated cytokine gradient. Stem Cells 27: 2646-2654.

114. Kim C, Lee KS, Bang JH, Kim YE, Kim MC, et al. (2011) 3-Dimensional cell culture for on-chip differentiation of stem cells in embryoid body. Lab Chip 11 : 874-882

115. Gilbert PM, Havenstrite KL, Magnusson KE, Sacco A, Leonardi NA, et al. (2010) Substrate elasticity regulates skeletal muscle stem cell self-renewal in culture. Science 329: 1078-1081.

116. Saha K, Keung AJ, Irwin EF, Li Y, Little L, et al. (2008) Substrate modulus directs neural stem cell behavior. Biophys J 95: 4426-4438.

117. JM Lee, Kim JE, Kang E, Lee SH, Chung BG, et al. (2011) An integrated microfluidic culture device to regulate endothelial cell differentiation from embryonic stem cells. Electrophoresis 32: 3133-3137.

118. Kim KM, Choi YJ, Hwang JH, Kim AR, Cho HJ, et al. (2014) Shear stress induced by an interstitial level of slow flow increases the osteogenic differentiation of mesenchymal stem cells through TAZ activation. PloS One 9: e92427.

119. Lucchetta EM, Munson MS, Ismagilov RF (2006) Characterization of the local 
temperature in space and time around a developing Drosophila embryo in a microfluidic device. Lab Chip 6:185-190.

120. Abaci HE, Devendra R, Soman R, Drazer G, Gerecht S (2012) Microbioreactors to manipulate oxygen tension and shear stress in the microenvironment of vascular stem and progenitor cells. Biotechnol Appl Biochem 59: 97-105.

121.Sim WY, Park SW, Park SH, Min BH, Park SR, et al. (2007) A pneumatic micro cell chip for the differentiation of human mesenchymal stem cells under mechanical stimulation. Lab Chip 7: 1775-1782.

122. Serena E, Figallo E, Tandon N, Cannizzaro C, Gerecht S, et al. (2009) Electrical stimulation of human embryonic stem cells: cardiac differentiation and the generation of reactive oxygen species. Exp. Cell Res. 315: 3611-3619.

123. Abe K, Niwa H, Iwase K, Takiguchi M, Mori M, et al. (1996) Endoderm-specific gene expression in embryonic stem cells differentiated to embryoid bodies. Exp Cell Res 229: 27-34

124. Itskovitz-Eldor J, Schuldiner M, Karsenti D, Eden A, Yanuka O, et al. (2000) Differentiation of human embryonic stem cells into embryoid bodies compromising the three embryonic germ layers. Mol. Med. 6: 88 .

125. Kurosawa $H$ (2007) Methods for inducing embryoid body formation: in vitro differentiation system of embryonic stem cells. J Biosci Bioeng 103: 389-398.

126. Bauwens CL, Peerani R, Niebruegge S, Woodhouse KA, Kumacheva E, et al. (2008) Control of human embryonic stem cell colony and aggregate size heterogeneity influences differentiation trajectories. Stem cells 26: 2300-2310.

127. Mohr JC, Zhang J, Azarin SM, Soerens AG, de Pablo JJ, et al. (2010) The microwell control of embryoid body size in order to regulate cardiac differentiation of human embryonic stem cells. Biomaterials 31: 1885-1893.

128. Panda P, Ali S, Lo E, Chung BG, Hatton TA, et al. (2008) Stop-flow lithography to generate cell-laden microgel particles. Lab Chip 8: 1056-1061.
129. Ma S, Natoli M, Liu X, Neubauer MP, Watt FM, et al. (2013) Monodisperse collagen-gelatin beads as potential platforms for $3 \mathrm{D}$ cell culturing. J.Mater. Chem. B1: 5128-5136

130. Allazetta S, Hausherr TC, Lutolf MP (2013) Microfluidic synthesis of cell-typespecific artificial extracellular matrix hydrogels. Biomacromolecules 14:11221131.

131. Headen DM, Aubry G, Lu H, García AJ (2014) Microfluidic-Based Generation of Size-Controlled, Biofunctionalized Synthetic Polymer Microgels for Cell Encapsulation. Adv. Mater. 26: 3003-3008.

132. Tumarkin E, Tzadu L, Csaszar E, Seo M, Zhang H, et al. (2011) Highthroughput combinatorial cell co-culture using microfluidics. Integr Biol (Camb) 3: 653-662.

133. Sakai S, Ito S, Inagaki H, Hirose K, Matsuyama T, et al. (2011) Taya M.Kawakami K. Cell-enclosing gelatin-based microcapsule production for tissue engineering using a microfluidic flow-focusing system. Biomicrofluidics 5: 013402.

134. Khademhosseini A, Langer R, Borenstein J, Vacanti JP (2006) Microscale technologies for tissue engineering and biology. Proc Natl Acad Sci USA 103: 2480-2487.

135. Richardson TP, Peters MC, Ennett AB, Mooney DJ (2001) Polymeric system for dual growth factor delivery. Nat Biotechnol 19: 1029-1034.

136. Wiegand C, Hipler UC (2013) A superabsorbent polymer-containing wound dressing efficiently sequesters MMPs and inhibits collagenase activity in vitro. J. Mater. Sci. Mater. Med. 24: 2473-2478.

137.Schwartz, Rogers RE, Singh SP, Lee JY, Lovelanwd SG, et al.(2013) A quantitative comparison of human HT-1080 fibrosarcoma cells and primary human dermal fibroblasts identifies a 3D migration mechanism with properties unique to the transformed phenotype. Plos One 8: e81689.
This article was originally published in a special issue, Molecules involved in cell signaling pathways handled by Editor(s). Dr. Masood Alam Khan, Al-Qassim University, Saudi Arabia 